\title{
RETHINKING RELIGIOUS FESTIVALS IN THE ERA OF DIGITAL ETHNOGRAPHY
}

\author{
Chiara Cocco and Aleida Bertran
}

\begin{abstract}
The Festival of Sant'Efisio has been carried out for centuries in Sardinia, Italy, to honor a vow made to the Saint after a plague in the seventeenth century. As a result of the global health crisis in 2020, the Festival was performed mainly through social media. Studying this event under such conditions accentuated the inherent complexity of interpreting ethnographic data from religious festivals, in which the body, emotions, and participation play a fundamental role. Emphasizing the hybridity of online and offline worlds, we reflect on how fieldwork has been transformed by COVID-19 through a reflexive account of the methodological challenges of online festival ethnography.
\end{abstract}

Keywords: festival ethnography, fieldwork, hybrid ethnography, pilgrimage, Sant'Efisio, Sardinia

The year 2020 will be remembered as a time when daily life was put on hold while communities were asked to stay at home. For ethnographers, the suspension of face-to-face encounters has intensified existing methodological debates about the nature of 'the field', posing new questions about the relationship between researcher and interlocutors. With little alternative, even researchers who rarely engaged with digital ethnography have embraced it despite the persistence of both social barriers and a digital divide. Nonetheless, online ethnographic research on religious rituals like the pilgrimage of Sant'Efisio Festival in Sardinia, Italy, offers a unique opportunity to rethink ethnographic knowledge production by drawing out the long-running parallels between pilgrimage and fieldwork as transformative experiences for both the pilgrim and the researcher (Helms 1988; Turner and Turner 1978). In this article we explore how the 2020 Festival of Sant'Efisio was moved from the streets to the Internet, 
and the impact that this shift had on the pilgrimage as well as our research. We explain how we have been dealing with the dynamics of being simultaneously in and out of an entirely virtual fieldwork, and how the blurred boundaries of the field have impacted the relationship between us and our interlocutors. Lastly, we illustrate how a hybrid approach helped navigate this "messy fieldwork environment" (Postill and Pink 2012: 126).

\section{The Festival of Sant'Efisio Online}

As social practices and ethnographic objects, festivals are collective phenomena, where gatherings are essential and the attendance and (co-)presence of people are indispensable. The performative nature of festivals is concerned with and deeply embedded in issues of identity as the "meanings and values of a group are embodied" (Bauman 1986: 133) publicly. The case study of the Festival of Sant'Efisio in Sardinia illustrates how the dynamic and participatory nature of religious ceremonies and festive celebrations encourages social cohesion and the construction of collective identities (Frost 2016; Leal 2016; Ramkissoon 2015). However, in times of isolation and social distancing, an event such as the Festival of Sant'Efisio, which typically brings together tens of thousands of people in the street (see fig. 1), was impossible.

The festival itself actually began with a vow made by the Cagliari City Council in 1656 in response to a plague that was decimating the Sardinian population. In return for the Saint delivering the city from the plague, every May

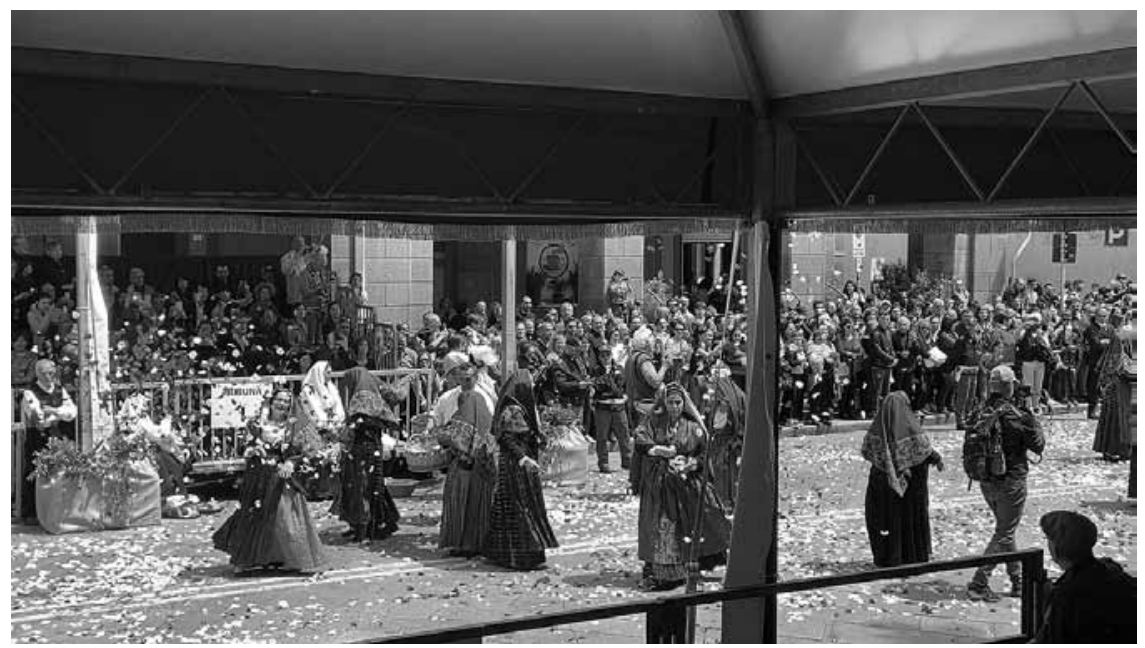

FiguRE 1: Festival of Sant’Efisio, 2019. Photograph ${ }^{\circledR}$ Chiara Cocco 
Sant'Efisio's statue is carried and followed by devotees in a pilgrimage that lasts four days and covers a total of 80 kilometers, accompanied by rituals and celebrations throughout the area. Since its origin, the procession has taken place annually except during the World Wars when it was shortened, downsized, or made secret to ward off crowds. The pilgrimage usually takes place within the first four days of May. However, in 2020 Italy was one of the countries most hit by the COVID-19 crisis, and all its regions were subject to strict lockdown regulations. Mobility was impeded except for essential business, gatherings of any sort were forbidden, churches were closed to the public, and funerals were performed with few or no family members present. Complying with the restrictions, the Prefecture, the Brotherhood of Sant'Efisio, and the City Council of Cagliari agreed to scale down the rituals, the performance of the vow, and key actors' participation, as well as to stream the festival on regional television and Facebook pages. The chosen date was 3 May, identified by the organizers as the authentic day of the fulfillment of the vow.

The uncanny analogy between the COVID-19 crisis and the circumstances in which the festival originated in the first place made the 2020 rendition not just extremely meaningful but also necessary for the community. Especially in a time of crisis and sorrow, people tend to return to their (often previously lost) faith in the divine and to seek hope and comfort in religious and traditional practice (Lorea 2020). This seems to be further enhanced by evocative memory work and the construction of new symbols and meanings. For instance, organizers chose to transport the statue on an Italian Red Cross military wagon, not just intentionally recalling the Saint's procession during the war in 1943, but also symbolizing the struggle of the community against the pandemic and earlier challenges that the annual pilgrimage had overcome.

In such a time of enforced seclusion, "individuals are made to look for new ways to reclaim the agency of lives lived under isolation" (Karampampas 2020: 292). This has translated into alternative forms to connect and feel connected, for example, by interacting through social media. In the words of the ethnologist Alessandro Testa (2020: 366), "forced into a state of domestication, the human animal seeks alternative forms of sociability, practising distant closeness across balconies and indulging in solitary gatherings through social media." This is also what occurred in the performance and participation of the festival, which reflected on Chiara Cocco's fieldwork experience. The social media streaming of the festival allowed people stuck in their homes worldwide to experience the festival, to feel part of the ritual, and to engage through digital interaction. Although the community could not come together physically, the online space allowed the creation of a closer 'imagined community' (Anderson 1983) across countries by expat Sardinians, such as Cocco, that would have otherwise been impossible. Some devotees posted prayers, photographs, and videos of their paraphernalia dedicated to the Saint to publicly 
display and demonstrate their faith and attachment to the ritual. However, this form of performance excluded or highly reduced the participation of social clusters, such as the elderly or children, who do not have access to the Internet or do not engage with social media.

The digital transformation of the pilgrimage of Sant'Efisio challenges received social scientific notions of what a religious ritual is. Since Durkheim (1912) wrote of 'collective effervescence', such rituals have often been seen as deriving their force from the power of many people coming together. Pilgrimages in particular are paradigmatic examples of liminal rituals in which people bond with each other and form spiritual communitas (Turner and Turner 1978), resulting in individual and social transformation (Helms 1988). The transformative potential of pilgrimages is also considered inherent in bodily movement, which is the embodied and performative action of pilgrimages (Coleman and Eade 2004). However, with rituals 'socially distanced', an interpretation of the pilgrimage as an inner spiritual experience (Turner and Turner 1978) might better explain the emotional and active engagement of the devotees with the solitary journey of the Saint. This was evidenced both by the high participation levels on social media and by the performance of some rituals on an individual level.

\section{Doing Digital Festival Ethnography}

Ethnographic fieldwork, as well as pilgrimage, can be looked at as a 'rite of passage' (van Gennep 1909) where the researcher embarks on a transformative journey and is in a constant state of being "betwixt and between" (Turner [1969] 1977: 95) personal and academic worlds. The interaction between the researcher and the field is a creative process of discovery, knowledge production, and deep transformation. In the words of Ullrich Kockel (2011: 205), “as fieldworkers, we make the field, but the field also makes us." These interpretations of fieldwork assume a live presence of the researcher in the field and 'deep hanging out' (Geertz 1998) with people and communities.

However, given the unprecedented circumstances of the pandemic, the entire ethnographic project and its approach needed to be reconsidered. The ethnographer, Cocco, was deprived of the whole range of sensations, encounters, and epiphanies she was eagerly awaiting in the field-the same way the pilgrims were deprived of the experiences of their ritual journey-and therefore of the transformative potential of ethnographic fieldwork.

New means of communication between the ethnographer and the informants have transformed and blurred the boundaries of the field as a shared geographical location. Yet at the same time, the field actually extends over time and space through mobile phones, the Internet, and social media (see fig. 2). As 


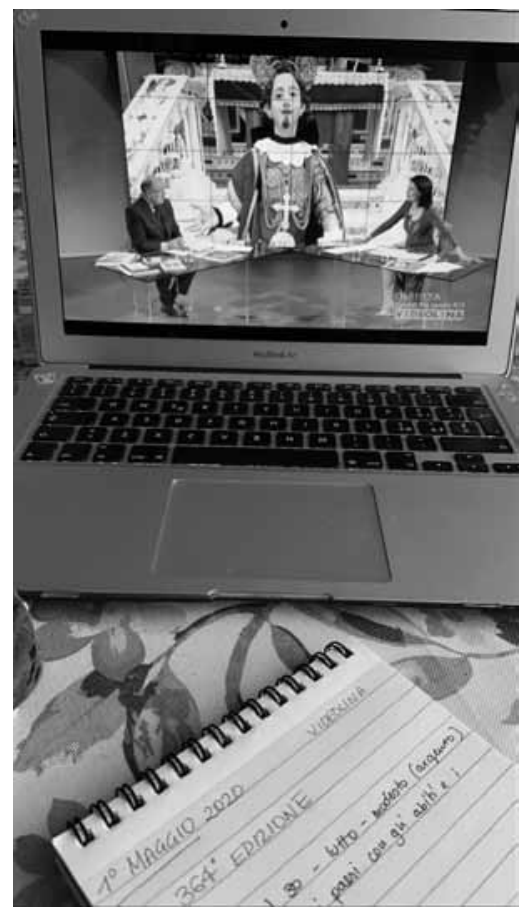

FIGURE 2: Fieldwork in 2020. Photograph ${ }^{\odot}$ Chiara Cocco

ethnographic encounters change, the fieldwork experience acquires new meanings for the researcher. In the time of distancing and isolation, for both the pilgrims and the ethnographer the value of 'being there' increasingly replaced that of 'being there' (Craith and Hill 2015): the value of experience became emphasized over that of presence (see also Hine 2015). Since virtual interviewing, video calls, and 'likes' have become the new frontier of ethnographic research methods, how can we consider fieldwork conducted while sitting at home as a transformative journey?

\section{Researching a Hybrid Field}

The Festival of Sant'Efisio has always been a quintessentially offline cultural practice, despite also being broadcast on radio and television. So its transformation into an online phenomenon raises a series of questions: Who constitutes the festival community amid a pandemic crisis? How do we measure the impact of the online festival and its transformative power for the community of faithful at large? 
Within this context, festival research transforms into a hybrid field, in which online and offline dimensions intersect to constitute a new reality with a sense of displaced symbolism. As Philipp Stockhammer (2012: 3) points out, the notion of hybridity exists in contrast to that of purity: "Every aim to transcend borders starts with the acknowledgment of those borders, confirming the existence of what needs to be overcome." Acknowledging the potential of hybrid ethnography is essential to overcome the boundaries of traditional festival research, in which offline participant observation is the norm. The ethnographer must become an agent capable of interpreting the festival community in times of exceptionality, embracing the unexpected impacts of isolation from 'normal' sociality-itself a new, globalized sociological phenomenon. The ethnographer has to learn to navigate through mediated connection, which entails deciphering intentionality in a performative digital culture (Leeker 2017). Here we outline the hybrid character of online research concerning an online/offline event with examples from three spheres: the ethnographer's participation in online performances, communication with interlocutors, and the ethnographic meeting space.

During the festival time in 2020, social media provided the participatory platforms for the community. A significant part of the festival community spontaneously engaged in a broad-based manifestation of online participation, in which creative materials and messages to engage with the festival were uploaded and shared. These activities represented a precious source of information for Cocco, who monitored the social media pages during the festival and the days preceding it. Moreover, as she had already established contacts with her informants in the previous year, they privately interacted with her by sending messages with comments, photographs, and videos in order to share their experience of the event with her. This form of network interaction is considered a key site within digital ethnography; it shows that participatory culture can be a collaborative method to co-produce knowledge between the researcher and the participants (Pink et al. 2016).

In Sant'Efisio 2020, online participatory culture also allowed the emergence of an offline form of participation, established by the devotees who most likely followed the festival on television but did not necessarily engage with the virtual festivities. For example, a singer and a local illustrator posted a video on Facebook of illustrations inspired by the festival, moving to the sound of the traditional prayers dedicated to Saint Efisio and encouraging the local community to collectively chant from their balconies. Hence, the virtual pilgrimage encouraged anonymous individual performances, creating a form of analogue-digital hybridity, in which the boundaries between the private and the public spheres became blurred. The unexpected musical element reinforced the symbolic value of Cagliari's streets as the Saint's journey path, echoing what Alessandro Falassi (1987: 4) defines as "the theater of festive events" in which "an area is reclaimed, cleared, delimited, blessed, adorned, forbidden to normal activities.” 
The festival's hybridity also transpired in the dynamics of ethnographic online encounters. The interviews were arranged through WhatsApp, Facebook, and e-mails - the most efficient media to get in touch with interlocutors-although they often exclude social groups without easy and immediate access to the Internet (Kuiper 2020). As the interlocutors were forced to stay in their homes, with very limited social contact outside their households, phone and video calls with the ethnographer were an opportunity to feel less isolated, enjoy some social time, and break the routine of quarantined life. As their commitments and engagements were reduced, most of the informants were eager to discuss their experiences for a relatively long period of time. This is an evident shift in festival ethnography, where most of the encounters are usually constrained by the fast pace of the festival environment, interlocutors' roles in the festival, and their private commitments. The time dilation associated with online festival encounters proved to be serendipitous for the ethnographer; it became an opportunity to establish an intimate connection built on shared affective experiences, which turned out to be transformative for the ethnographer. Some of the interlocutors shared their personal experiences with the researcher, and others were brought to tears when discussing their devotion to the Saint. In this case, virtual reality unveiled the emotional dimension of the festival through moments of individual catharsis, which enabled a new form of social bonding.

Another manifestation of online hybridity can be found in the intimacy created by the interlocutors' home environment and the presence of the researcher. During the online encounters, the realm of the informants' homes became a source of knowledge for the ethnographer, as it would in an offline circumstance. Many interlocutors spontaneously chose to reveal their emotional attachment and devotion to the Saint by showing paintings or sculptures and festival-related objects. These cultural artifacts, as memory shapers (Rigney 2016), provided the context for the development of the interlocutors' stories and personal contributions. Thus, the online exchange helped the ethnographer to understand the anatomy of the festival and the symbolic elements present in the daily life of the community that will provide meaning during the wait for the next festival. This dimension of mediated connection made accessible similar ethnographic impressions that the researcher would have had in an offline encounter, allowing a certain degree of materiality to be present digitally.

\section{Conclusion}

The different forms of hybridity that our online festival ethnography encountered in May 2020 highlight the complexity of the concepts of body, embodiment, and participation. The corporeal dimension of the festival and its emphasis on co-presence, which are the traditional sources of the festival's 
coherence for ethnographers, were absent under pandemic conditions. The festival experience moved from the public square to the private sphere of people's homes through digital media as the community came to embody the festival's emotional dimension. As the boundaries of the performance and the relation between the individual and the collective space of the festival became blurred, the experience of fieldwork and pilgrimage as 'journeys' changed. The self-awareness of this shift and the ability to adapt and reinterpret the pilgrimage and its ritual in a time of exceptionality delineated a transformative journey for the ethnographer, who had to rediscover the field in a mediated reality, as well as her relation with her interlocutors. This case study has shown how the hybridity of online and offline participation in the festival gave both the devotees and the researcher the opportunity to come together and build collective experiences in this unprecedented time of crisis and isolation.

\section{Acknowledgments}

We wish to express our most sincere gratitude to Anna-Maria Walter and Geoffrey Hughes for their kind and valuable input and careful reading of draft versions of this article. The review and insightful comments of Cristina Clopot are also gratefully appreciated.

Chiara Cocco is a PhD student in the Department of Languages and Intercultural Studies at the Heriot-Watt University, Edinburgh. She holds an MSc in Cultural Resource Management, obtained at the Heriot-Watt University in 2017. Her research interests include ethnographic methods in festival studies and cultural heritage research. She is also interested in performance theory and liminality, identity, and gender. Her current research project explores the performance of heritage and identity in cultural festivals by analyzing the Festival of Sant'Efisio in Sardinia. She is also an active member of the Intercultural Research Centre (IRC) in Edinburgh. E-mail: cc80@hw.ac.uk

Aleida Bertran is a PhD student at the Latvian Academy of Culture. She holds a BA in Translation and Interpreting Studies at the Autonomous University of Barcelona and an MSc in Cultural Resource Management at Heriot-Watt University, Edinburgh. This multidisciplinary background has led to an interest in political ethnography, social movements, and cultural minorities. Her research focuses on a comparative study of folk festivals and national identity in the Baltic states and Catalonia. She has also been a Lecturer of the course Social Movements and Culture at her university. E-mail: aleida.bertran@gmail.com 


\section{References}

Anderson, Benedict. 1983. Imagined Communities: Reflections on the Origin and Spread of Nationalism. London: Verso.

Bauman, Richard. 1986. "Performance and Honor in 13th-Century Iceland.” Journal of American Folklore 99 (392): 131-150.

Coleman, Simon, and John Eade, eds. 2004. Reframing Pilgrimage: Cultures in Motion. London: Routledge.

Craith, Máiréad Nic, and Emma Hill. 2015. "Re-locating the Ethnographic Field: From 'Being There' to 'Being There.'” Anthropological Journal of European Cultures 24 (1): 42-62.

Durkheim, Émile. 1912. Les formes élémentaires de la vie religieuse [The elementary forms of religious life]. Paris: Presses Universitaires de France.

Falassi, Alessandro. 1987. "Festival: Definition and Morphology." In Time Out of Time: Essays on the Festival, ed. Alessandro Falassi, 1-10. Albuquerque: University of New Mexico Press.

Frost, Nicola. 2016. “Anthropology and Festivals: Festival Ecologies.” Ethnos 81 (4): 569-583.

Geertz, Clifford. 1998. “Deep Hanging Out.” New York Review of Books 45 (16): 69-72.

Helms, Mary W. 1988. Ulysses' Sail: An Ethnographic Odyssey of Power, Knowledge, and Geographical Distance. Princeton, NJ: Princeton University Press.

Hine, Christine. 2015. Ethnography for the Internet: Embedded, Embodied and Everyday. London: Bloomsbury Academic.

Karampampas, Panas. 2020. "Partying at Times of Crises and Pandemics: Solidarity, Resilience and Coping with the Measures against COVID-19.” Social Anthropology 28 (2): 292-293.

Kockel, Ullrich. 2011. "Morphogenetic Fieldwork and the Ethnologic of Toposophy: Meditation on a Coyote Wandering on Rannoch Moor.” In Beuysian Legacies in Ireland and Beyond: Art, Culture and Politics, ed. Christa-Maria Lerm Hayes and Victoria Walters, 195-219. Berlin: LIT Verlag.

Kuiper, Gerda. 2020. “Ethnographic Fieldwork Quarantined.” Social Anthropology 28 (2): 300-301.

Leal, João. 2016. “Festivals, Group Making, Remaking and Unmaking.” Ethnos 81 (4): 584-599.

Leeker, Martina. 2017. "Performing (the) Digital: Positions of Critique in Digital Cultures.” In Performing the Digital: Performance Studies and Performances in Digital Cultures, ed. Timon Beyes, Martina Leeker, and Imanuel Schipper. Bielefeld: transcript.

Lorea, Carola Erika. 2020. "Religious Returns, Ritual Changes and Divinations on COVID-19." Social Anthropology 28 (2): 307-308.

Pink, Sarah, Heather Horst, John Postill, Larissa Hjorth, Tania Lewis, and Jo Tacchi. 2016. Digital Ethnography: Principles and Practice. London: Sage.

Postill, John, and Sarah Pink. 2012. "Social Media Ethnography: The Digital Researcher in a Messy Web.” Media International Australia 145 (1): 123-134. 
Ramkissoon, Haywantee. 2015. "Divali Festival in Mauritius: The Development of a Conceptual Framework for Understanding Attitudes towards and Intentions to Celebrate Traditional Cultural Festivals." In Rituals and Traditional Events in the Modern World, ed. Jennifer Laing and Warwick Frost. Abingdon-onThames: Routledge.

Rigney, Ann. 2016. "Cultural Memory Studies: Mediation, Narrative, and the Aesthetic.” In Routledge International Handbook of Memory Studies, ed. Anna Lisa Tota and Trever Hagen, 65-76. London: Routledge.

Stockhammer, Philipp Wolfgang. 2012. “Questioning Hybridity.” In Conceptualizing Cultural Hybridization: A Transdisciplinary Approach, ed. Philipp Wolfgang Stockhammer, 1-3. Berlin: Springer.

Testa, Alessandro. 2020. "Where Have the Gatherings Gone? Reweaving the Social Fabric in the Time of Pandemic and Interpersonal Distancing." Social Anthropology 28 (2): 366-367.

Turner, Victor. (1969) 1977. The Ritual Process: Structure and Anti-Structure. New York: Cornell University Press.

Turner, Victor, and Edith Turner. 1978. Image and Pilgrimage in Christian Culture: Anthropological Perspectives. New York: Columbia University Press.

van Gennep, Arnold. 1909. Les rites de passage [The rites of passage]. Paris: Émile Nourry. 